The final paper was by Prof. D. M. Newitt, Courtaulds professor of chemical engineering in the Imperial College of Science and Technology, London, who discussed the scope and nature of the research which can appropriately be undertaken in a teaching department of chemical engineering.

The final summing-up of the results of the Conference was made by Sir Harold Hartley, who said : "What has become abundantly clear to me as the days progressed is that, with one partial exception, there is a general agreement among the European countries represented here as to the conception of chemical engineering as a fourth primary technology which now takes its place alongside the other professions of civil, mechanical and electrical engineering. And I know that that view is shared by all the countries of the British Commonwealth. That is the first major result of our Conference and it is one of great importance. We did not know until now the degree of unanimity that existed between us. The second result is to show that there is a large unsatisfied demand for chemical engineers, and consequently a need to expand and multiply the schools of engineering in each country ... we have already examined the need for more research and the lines on which it should proceed and the advantage of closer co-operation between us. So we have answered two questions put to us in the affirmative. For the third we must rely on the Press, and I hope that our nomenclature has not been too technical to obscure the main issues".

Coming to the partial exception, he said: "Let me begin by expressing our admiration and our indebtedness to Germany for what she has contributed in the field which we like to call chemical engineering. Let me remind you of what the world owes to Adolf Baeyer and Emil Fischer and their pupils and to the Haber process, of those great pioneer developments of the synthetic industry in Germany around about 1900. I shall never forget the impression made on $m e$ by the imaginative chemical engineering of the Haber plant at Ludwigshafen when I first saw it. Now our German friends, for good reasons from their experience, have chosen rather a different approach to us. Let me say at once that we admire the skill of their Verfahrens Ingenieure, which is seen to such advantage in the mechanical design of their plants. We could do with more of that same breed in other countries, particularly in the field of plant manufacture. Their Verfahrens Ingenieure represent one band in Sir Christopher Hinton's spectrum, or one arm of Prof. Donald's distribution curve. I must say that I was greatly comforted by what Prof. Schoenemann said of the need to supplement the classical chemist by the chemical technologist, and how unfortunate it would be if the need for process engineers were to hinder the technological education of a number of chemists. Thereby he is building $a_{0}$ bridge between our different approaches. Chemical engineering is still a very young profession; it is dynamic and it is in the stage of rapid evolution. So it is no wonder that there are different patterns, and it is all to the good that it should develop on independent lines in different countries and universities. It is its adaptability and its flexibility that are its great strength. As Mr. White said, its ubiquity is its most marked characteristic. Its techniques are invading almost every industry and the hope of satisfying the world's growing demands depends more and more on chemical engineering, call it by what name you will".

\section{INSTITUTE OF PHYSICS EDUCATION GROUP CONFERENCE}

A $\mathrm{T}$ the annual conference of the Education Group A of the Institute of Physies, held on April 14 and 15, with Dr. J. Topping as chairman, the teaching and applications of thermodynamics, and the place of physics in a liberal education were the subjects of the main contributions.

Prof. E. A. Guggenheim (University of Reading), speaking on "Fundamentals of Thermodynamics", said that the first concept for the beginner should be free energy, and the subject should be developed from the Gibbs-Helmholtz equation, which would be presented as an axiom in a purely classical treatment, or as a consequence of the distribution law in terms of statistical mechanies. Entropy, and the distinction between reversible and irreversible changes, should not be introduced too early. The student should proceed in stages from simple isothermal reversible cases, working always in terms of decrease in free energy rather than of entropy increase.

The achievements and problems of the heat engineer were described by Dr. G. G. Haselden (Imperial College of Science and Technology, London) in a paper on "Thermodynamics in Industry". The development of new materials for high temperatures at which the heat acceptance of an engine can match the heat liberation of the fuel, the search for cycles more efficient than those based on the constanttemperature evaporation of water, and the choice of the best cycle for the gas turbine, are among the applications of thermodynamics to large-scale power generation. Also, by exposing the low efficiency of the turbine system, thermodynamics has stimulated the search for the fuel cell, which has already, so far as gaseous fuel is concerned, reached a promising stage. While the seasonal fluctuation of the heatpump's output and its high capital cost make it uneconomic as an ordinary means of heating in Britain, it is more attractive in chemical industry, to bridge the small interval between the temperatures at which heat is given out by one process and absorbed by another, as, for example, in a sugar evaporation cycle.

In designing air liquefaction and separation systems, the components are matched to the properties of air (to eliminate discontinuous latent heat jumps) as in the Heylandt process, where the expansion engine operates in the supercritical region, and the interchanger below it. Ideally, heat should be supplied and extracted at every level in an air separation column, and heat pumping is now used for supplying or extracting in several places instead of at the extremes. Following Ruhemann's analysis of the entropy increases at various stages of the Linde system, the aim is to approach reversibility at each stage. As a result, air-separating plants have been made which operate at an efficiency of 23-25 per cent, compared with a theoretical efficiency of 35 per cent and the 12 per cent of the original Linde double column.

Opening a discussion on the teaching of thermodynamics, Prof. M. W. Thring (University of Sheffield) outlined the organization of classes for various groups at the University of Sheffield, and mentioned the importance of the emotional attitude towards the subject, and its various functions. Free energy is a 'good' function, and entropy a 'bad' function the increase of which is to be discouraged-gain of 
entropy by a system representing a positive loss of virtue. Clarity is necessary in distinguishing between the 'first-law' efficiency of a system and the thermodynamic efficiency. Dr. N. Kurti (Clarendon Labor. atory, Oxford) deplored the conventional distinction between heat and thermodynamics, and suggested that a single course, implanting faith in thermodynamics by the statistical approach, should serve for all university students whatever their specialist interests. Dr. R. S. Silver (John Brown Land Boilers, Ltd., Clydebank) presented the practical engineer's point of view. Thermodynamics, he said, is badly taught because its concepts are of a subtlety beyond the grasp of the average physicist and the average teacher. Hence, the exposition of the second law is not normally adequate to equip the engineer to face industrial problems. He advocated teaching in terms of ordered and disordered energy rather than work and heat-ordering rather than energy conversionand abandoning the usual idea of efficiency for a proportioning ratio between ordered and disordered energy expressed in terms of temperatures.

Dr. A. W. Barton (City of London School) opened the second day's proceedings, speaking on "Physics in the School Curriculum". The historical development of the subject is a treatment which marches in line with the development of the individual boy, with the early passion for collecting facts and slowly emerging capacity to relate them to general principles. Physics is, he said, an educational discipline equalled only by Greek. Dr. Barton's lively exposition of his own teaching methods was a memorable feat, which illustrated his general argument convincingly.

Mr. W. Llowarch (Institute of Education, London) spoke on "Non-Specialist Science in the Sixth Form", outlining the scheme he developed during his time at Stowe School. For a year's course, the boys were divided into three groups, each doing one term of biology, physics and chemistry in rotation, the work being taught by specialists. Lectures on isolated subjects of special or topical interest had proved on the whole preferable to a more continuous course, and biology seemed the most generally appreciated of the three. After discussing the aims of the course, Mr. Llowarch gave some examples of topies which had been particularly successful.

"Education through Physics" was the title of the talk by Prof. F. A. Vick (University College of North Staffordshire). One of the aims of education, he said, is to toughen the mind by exercise on problems. The historical approach, while not generally useful, can be valuable in showing the devious routes by which accepted theories arose. Students should be encouraged from the beginning to consult original papers, and in the final year at the university, while continuing a broad education, should reach the frontiers of knowledge in one or two places. In subsidiary physies courses, the future technologist should regard the subject not as a mere tool, but as a contribution to his full education. Prof. Vick regards physics, freed from the mechanistic outlook of the nineteenth century, as a living subject which stands equal to classical and modern studies as the core of a complete education.

Mr. N. R. Hanson (University of Cambridge) then described the undergraduate course in the history and philosophy of science, developed during the past five years in the University of Cambridge. The aim, he said, is not to bumanize the scientist by superposing a little culture, but to help him to understand what he is doing. History leads to a better appreciation of an idea by tracing the steps in its development. Philosophy, as concerned with the meaning of concepts, and why they are fashioned in one way rather than another, may help a man to be a better physicist. Mr. Hanson explained the close collaboration by which the course is dovetailed with the tripos lectures in physics, and spoke of the enthusiasm with which it has been received, and the growth of the Philosophy of Science Club at Cambridge.

G. R. NOAKES

\section{PROPOSED MUSEUM OF SCIENCE AND TECHNOLOGY IN THE NORTH-WEST OF ENGLAND}

A MEETING was held on February 18 at the A College of Technology, Manchester, to consider a proposal to establish a museum of science and technology in the north-west of England. Interest in such a museum came from a number of quartersfrom industry and from academic and educational life. Sympathy and support for this scheme has also been shown by municipal and other bodies. The meeting was attended by representatives of industry, the universities, trade and professional bodies and representatives of museums in Manchester, York, Birmingham and Liverpool.

A resolution was moved by Mr. L. Lever, M.P., and Dr. P. F. R. Venables, and carried unanimously, that a museum of science and technology be established, and an executive committee be appointed in order to investigate the details involved in setting such a project in action, and to report back at a subsequent meeting of the body as ihen constituted. The executive committee consists of Mr. H. G. Greg (for the Textile Institute), Mr. Niel Pearson, Prof. L. Rosenfeld (Department of Theoretical Physics, University of Manchester), Mr. R. M. Sayce (keeper, Manchester Museum) and Dr. P. F. R. Venables (principal, Royal Technical College, Salford); Mr. P. Lennox-Kerr (editor, Skinner's Silk and Rayon Record) and Dr. W. Mays (Department of Philosophy, University of Manchester) are the joint secretaries.

The project for a museum of science and technology arose from the joining together of two streams of interest. In industry, especially the textile and engineering industries, there has for a long time been felt the need for establishing an industrial museum to take account, among other things, of the economic history of the region. At the University of Manchester there was a group of people interested in the establishment of a museum for the history of science and technology. It was felt by them that the history of science should take a more important place in university education, where there is an everincreasing need for relating the diverse fields of study which make up the university curricula. In the promotion of the study of the history of science, a museum plays an essential part, comparable to that of a laboratory in the experimental sciences.

The intention is to establish a science museum which will show the development of industry in the northwest of England from the early days of the Industrial Revolution to the present day in relation to the scientific background. It is hoped that it will embrace a number of fields of inquiry-from the natural sciences to economic history-and lead to 